\title{
Balanced Scorecard Adaptation using AHP for the Corporate Healthcare Sector in India
}

\author{
Stephen Victor, Ayesha Farooq
}

\begin{abstract}
The Balanced Scorecard(BSC) developed in the 1990s as a performance management tool finds significant applications in several areas including healthcare. Healthcare Industry though was slow in utilising the BSC due to complications in data sourcing and its management. The varied nature of data generated and handled in the process of healthcare delivery poses a challenge in measuring and prioritising the Key Performance Indicators(KPI). In the present study, to tackle this challenge the Analytic Hierarchy Process(AHP) which uses mathematical modelling and powerful synthesis for combining data and judgement to effectively rank options and predict outcomes has been applied. Here, the AHP was used to develop a comprehensive BSC that will not only give priorities within each perspective of the BSC but also provide an overall ranking list to aid performance management. Twenty senior administrators from a Corporate Hospital in India took part in the AHP exercise to give their pairwise choices for all the KPIs. The eigenvector method of the AHP aided in consolidating and processing their collective opinions to give a scientifically designed BSC framework. To ensure data validity in terms of consistencies and to perform the complex calculations involved, the Business Performance Management Singapore (BPMSG) template was used. By adopting the Row Geometric Mean Method this template provided the final output in an easy-to-read graphical form which can be displayed on a digital dashboard. The primary advantage of this method of display is the flexibility it permits in modifying the target values of the KPIs, realtime. The outcome of this study is expected to provide strategic directions to the hospital. The developed BSC framework is also expected to provide a benchmark for other similar healthcare institutions across India.

Keywords: Balanced Scorecard(BSC), Key Performance Indicators(KPI), Analytic Hierarchy Process (AHP), Performance Management, Healthcare
\end{abstract}

\section{INTRODUCTION}

The pandemic caused by the novel Covid-19 virus has brought healthcare into limelight across the world. Though the importance given to other diseases have considerably reduced, their threats have in no way diminished. To tackle this surging demand for healthcare services, effective models should help reduce costs without affecting the quality and timeliness of the services offered. A framework that promises to significantly aid in making healthcare delivery better is the Balanced Scored(BSC). The Indian healthcare industry has utilised the BSC to a very limited extent. One of the reasons the BSC has not gained popularity is the lack of a tool to help assign the degree of importance to the Key Performance Indicators(KPI).

Revised Manuscript Received on August 13, 2020.

* Correspondence Author

Stephen Victor*, Associate Professor, Business Management, PCTE, Ludhiana, Punjab, India.

Prof. Ayesha Farooq, Associate Professor, Business Management, PCTE, Ludhiana, Punjab, India.

(C) The Authors. Published by Blue Eyes Intelligence Engineering and Sciences Publication (BEIESP). This is an open access article under the CC BY-NC-ND license (http://creativecommons.org/licenses/by-nc-nd/4.0/) performance management models need to be created. Such

In this context, the AHP can be employed to help organisations choose priority focus areas. The effectiveness of the BSC framework is thus enhanced with the use of the AHP.

\section{LITERATURE REVIEW}

\section{A. Healthcare BSC}

A study concluded that BSC's innovativeness ranks among the top innovations of the $20^{\text {th }}$ century[1]. The impact of the BSC has been widespread covering a variety of fields. The Gartner Group estimated that at least $50 \%$ of all Fortune 1000 companies use the BSC methodology[2]. The popularity of the BSC lies in the fact that it is a measurement system, not just a management system which gives strategic directions to accomplish its Vision and fulfil its Mission. The BSC has ample flexibility to be applied to a range of fields including healthcare. In the healthcare field, complex relationships exist between the different perspectives of the BSC. The major complexity is due to the need for making comparisons and arriving at the relative importance of KPIs in different perspectives[3]. This is crucial because efficient and progressive teams associated with important KPIs should be given sufficient opportunities and the importance of their assessments should not be undermined. Similarly, excessive attention and allocation of resources to less valuable KPIs will lead to a big disadvantage to the institution. Studies have proved that the usage of BSC leads to an increase in the accuracy of measurements and health outcomes[4].

\section{B. Key Performance Indicators(KPI)}

KPIs are metrics related to important business processes. These are mileage markers which indicate whether the regular activities are truly focussed on the achievement of organisational goals. KPIs are beneficial because they are scalar measures which can be used for evaluation. Before inclusion of a KPI in the BSC, the question, "What must we excel at?"[5] needs to be answered. When measured to a fair degree of accuracy, KPIs confirm that the business establishment is fulfilling its primary objective of financial growth. Poorly selected KPIs can affect performance because of their lag effect[6]. Lag indicators show only historical performances and therefore are not as beneficial as compared to lead indicators in monitoring and making course corrections for enhancing performance. According to Parmenter, the terms lag and lead indicators refer to outcomes and performance drivers respectively[7]. In constructing the BSC, the focus should be to ensure that the KPIs selected are lead indicators since they are more likely to lead to business viability and success.

Published By:

Blue Eyes Intelligence Engineering \& Sciences Publication 


\section{Balanced Scorecard Adaptation using AHP for the Corporate Healthcare Sector in India}

\section{Analytic Hierarchy Process (AHP)}

Thomas L. Saaty's seminal work in the 1970s led to the formulation of "The Analytic Hierarchy Process (AHP)". AHP's structured approach helps in measuring intangibles utilising human judgment[8]. The methodology adopted by AHP can be understood by an appropriate algorithm developed by mathematical modelling which leads to a powerful synthesis of merging judgement and data to effectively arrive at priorities. A research study proved that for decision-making in a multi-criteria environment AHP can be applied to identify and prioritize strategic focus[9]. The rudimentary method of AHP's functioning is pairwise comparisons between two KPIs at any instant. When evaluators compare a pair at any point in time, they make better choices than when they have to choose from many options judged simultaneously. Pairwise comparison as a means of making the optimum choice was proposed in the 18th Century by Condorcet. Condorcet proposed an election method that elected the candidate who won the maximum number of votes in all of the head-to-head pairwise voting processes[10]. Rather than compelling an exact decision, this method assists decision-makers to arrive at a solution that is most suitable to their objectives. According to Vargas who researched problem resolving frameworks, making use of the AHP approach leads to gainfully utilizing both quantifiable and intangible criteria[11]. The AHP approach has been widely applied in several different decision-making needs including policy-making, strategy formulation, and resource allotment[12]. Furthermore, in problem-solving environments requiring multiple decisions such as introducing ranking, benchmarks, prioritization and making choices, AHP can be applied[13]. Another specific benefit that accrues from the use of AHP is the timeliness of making decisions. AHP also gives the scientific basis to choose important KPIs by creating deep insights into previous performances. This leads to success by making appropriate projections and providing a simple approach to differentiate between targets given by corporate strategists and the actual achievement[9]. The AHP uses the data collected from the pairwise comparisons and arranges them in the form of a matrix. The basis of the AHP method is arriving at the principal eigenvector. Matrices created by all respondents are multiplied to get the geometric mean which is the first step in calculating the eigenvector. Next, the values in each row are multiplied which forms the product matrix. The product matrix undergoes the n-th root calculation of the row elements. To get the principal eigenvector the sum of the columns are used to normalize the numbers which show weights of the KPIs. Saaty showed that the principal eigenvectors are the weights of the required priorities[14]

\section{BSC adaptations using AHP}

The adaptation of BSC tool with the AHP assures an advantage in that it allows emphasis on the interrelations between the different decision-making factors and facilitates locating KPIs that are more conformable with the Vision and Misson of the organisation. AHP can be applied in circumstances wherein key stakeholders can rank pairwise items concurrently to reach consensus[15]. Thus a diversity of sentiments can be channelised to benefit the organisation in a consistent and harmonised manner. Individual involvement ensures greater earnestness and attention from the key decision-makers. Therefore, BSC usage for gauging performance when used with AHP leads to more acceptance by avoiding conflicts. A study by Dey et.al concluded that the use of AHP in creating BSC frameworks by combining processes and outcomes with structure-based KPIs leads to performance enhancement in healthcare delivery. [16] Another advantage of using the AHP in BSC applications has been documented by Leung et al. They pointed out that the AHP is versatile in overcoming chronic difficulties that arise with BSC usage, like, comparing subjective perspectives and determining the contribution of individual perspectives[17].

\section{RESEARCH METHODOLOGY}

The AHP uses a geometric scale of comparisons between element $\mathrm{A}$ and $\mathrm{B}$. The judgement scale guide for comparisons between the two elements is shown in Table 1

Table 1: AHP Geometric Scale Guide [19]

\begin{tabular}{|c|c|c|}
\hline $\begin{array}{l}\text { Intensity of } \\
\text { Impertance }\end{array}$ & Definition & Explanation \\
\hline 1 & Equal importasee & $\begin{array}{l}\text { Element } \boldsymbol{A} \text { and } \boldsymbol{B} \text { contribute equally to the } \\
\text { objective }\end{array}$ \\
\hline 3 & $\begin{array}{l}\text { Moderate } \\
\text { importance of one } \\
\text { over another }\end{array}$ & Stighaly favour element $A$ ores $B$ \\
\hline$s$ & Esveatial importance & Strongly favour element $\boldsymbol{A}$ over $\boldsymbol{B}$ \\
\hline 7 & $\begin{array}{l}\text { Demonstrated } \\
\text { importance }\end{array}$ & Element $\boldsymbol{A}$ is favoured very strongly over $\boldsymbol{B}$ \\
\hline 9 & Absolute importasce & $\begin{array}{l}\text { The evideace frvouriag element over } A \text { over } B \text { is } \\
\text { of the highest possible order of importance }\end{array}$ \\
\hline $2,4,6,8$ & $\begin{array}{l}\text { Intermediate valaes } \\
\text { between the two } \\
\text { adjacent jodgments }\end{array}$ & $\begin{array}{l}\text { When compromise is needed. For example, } 4 \text { can } \\
\text { be used for the intermediate value between } 3 \text { and } 5\end{array}$ \\
\hline $\begin{array}{l}1 / 3,1 / 4,1 / 5 \\
1 / 6,1 / 7,1 / 8 \\
1 / 9\end{array}$ & \multicolumn{2}{|c|}{$\begin{array}{l}\text { These values repteseat the opposite of the reciprocal whole numbers. For } \\
\text { example, if } 9 \text { meess that } x \text { inuch more important than } y \text {, "1/9" mesns } \\
\text { that } x \text { is mush less importast thas } y \text {. }\end{array}$} \\
\hline
\end{tabular}

The data collection is followed by the estimation of the principal eigenvector of the pairwise matrix.

An eigenvector of a square matrix $\mathrm{A}$ is a non-zero vector $\mathrm{X}$ such that for some number $\lambda$, the following equation is formed:

$\mathrm{AX}=\lambda \mathrm{X}$ is called $\lambda$ an eigenvalue

To find the eigenvalues of an $n X n$ matrix [A] we have

$$
\begin{aligned}
& {[\mathrm{A}][\mathrm{X}]-\lambda[\mathrm{X}]=0} \\
& {[\mathrm{~A}][\mathrm{X}]-[\lambda][\mathrm{I}][\mathrm{X}]=0} \\
& ([\mathrm{~A}]-[\lambda][\mathrm{I}])[\mathrm{X}]=0
\end{aligned}
$$

$$
I=\left(\begin{array}{llll}
1 & 0 & 0 & 0 \\
0 & 1 & 0 & 0 \\
1 & 0 & 1 & 0 \\
0 & 0 & 0 & 1
\end{array}\right)
$$

For the requirement of a non-zero solution,

$$
\operatorname{det}([A]-\lambda[I])=0
$$

Published By:

Blue Eyes Intelligence Engineering 
To get the eigenvalues, solve the polynomial that arises on the left-hand side.

$$
\lambda^{n}+c_{1} \lambda^{n-1}+c_{2} \lambda^{n-2}+--+c_{n}=0
$$

Since AHP involves complex arithmetic calculations involving matrices developed from the pairwise choices, the calculations were done using the "Business Performance Management Singapore (BPMSG)" template created by D Klaus Gospel. The BPMSG was first presented in the "International Symposium on the Analytic Hierarchy Process"[18]. The macros inbuilt in the BPMSG complete the arithmetic calculation and estimate the principal eigenvector of the pairwise matrices. The hospital administrators gave their pairwise judgements on a geometrical scale between 1 and 9. The BSC adaptation using AHP was undertaken for corporate tertiary Hospital in India. Senior Administrators and decision-makers from different departments took part in the AHP study. The respondents gave their pairwise choices in separate Excel sheets. A sample of such a sheet is shown in Figure 1.

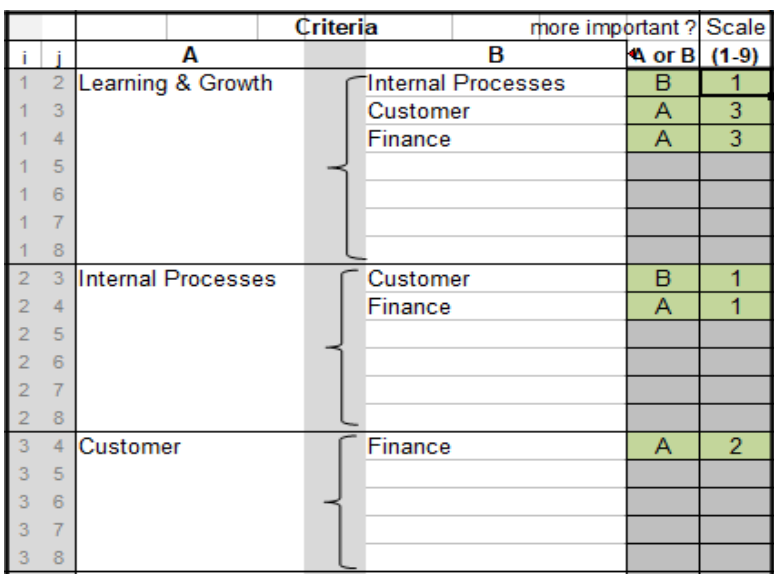

Figure 1. Sample Excel sheet for inputs [20]

The inputs received from the participants were checked for the following consistencies

i. Consistency Ratio(CR)

ii. Geometric Consistency Index(GCI)

Consistency Ratio: When pairwise judgments are received from several respondents, their choices are to be verified for inconsistencies. The method of calculating the CR starts with the estimation of the Consistency Index (CI).

The $\mathrm{CI}$ is calculated using the relation

$$
C I=\frac{\lambda_{\max }-n}{n-1}
$$

$\lambda_{\max }$ is the maximum eigenvalue and $\mathrm{n}$ is the number of variables or the matrix size

CR is the ratio of CI and Random Consistency Index (RI). $\mathrm{RI}$ when $\mathrm{n}=4$ is 0.9 [21]

$$
C R=\frac{C I}{R I}
$$

According to the finding by Saaty, the Consistency Ratio(CR) when taken as a percentage cannot exceed 10 [19]. The reliability of the data becomes questionable when the CR exceeds $10 \%$.

Geometric Consistency Index: This is another measure that ensures the validity of the collected data. GCI is defined as "the normalized total of the local contributions to the inconsistency"[22]. The GCI thresholds assist in understanding and interpreting the level of tolerances. Aguarón et.al have worked on the GCI threshold and have deduced that when $n=4$ is GCI limit is $0.3526[23]$.

\section{IV.RESULTS AND FINDINGS}

The results were obtained by the Row Geometric Mean Method which provided the comparative priorities of the perspectives as well as the KPI priorities for each of the BSC components. To ensure that the values obtained are valid, both CI and GCI were checked for all the responses individually. Table 2 shows the consistencies of the BSC perspectives.

Table 2: CI and GCI for the respondents

\begin{tabular}{|c|l|c|c|}
\hline Sl. No. & Description & CI \% & GCI \\
\hline 1 & $\begin{array}{l}\text { Balanced Scorecard } \\
\text { Perspectives }\end{array}$ & 1.6 & 0.06 \\
\hline 2 & Learning \& Growth & 0.9 & 0.03 \\
\hline 3 & Internal Processes & 0.6 & 0.02 \\
\hline 4 & Customer & 6.4 & 0.23 \\
\hline 5 & Finance & 3.8 & 0.14 \\
\hline
\end{tabular}

Since the values of both CI and GCI are within the limits (CI - 10\%. GCI - 0.3526) the inputs are considered as credible. On completion of the arithmetic calculations, BPMSG excel macro provided a summary sheet in the form of a final matrix. This is the average value of the judgements given by

\begin{tabular}{|c|c|c|c|c|}
\hline \multirow[b]{2}{*}{ Description } & $\begin{array}{c}\text { Learning } \\
\& \\
\text { Growth }\end{array}$ & \begin{tabular}{|c} 
Internal \\
Processes
\end{tabular} & Customer & Finance \\
\hline & \multicolumn{4}{|c|}{$\begin{array}{l}\text { Final matrix of judgements given by the } \\
\text { respondents }\end{array}$} \\
\hline $\begin{array}{l}\text { Learning \& } \\
\text { Growth }\end{array}$ & 1.000 & 3.000 & 3.000 & 5.000 \\
\hline $\begin{array}{l}\text { Internal } \\
\text { Processes }\end{array}$ & 0.333 & 1.000 & 1.000 & 3.000 \\
\hline Customer & 0.333 & 1.000 & 1.000 & 3.000 \\
\hline Finance & 0.200 & 0.333 & 0.333 & 1.000 \\
\hline Total & 1.866 & 5.333 & 5.333 & 12.000 \\
\hline
\end{tabular}
the 20 respondents. See Table 3.

Table 3: Final matrix of the judgements

The eigenvalue is arrived at in a two-step process. In the first step, all the row values are divided by the column total and in the second step row-wise averages are calculated. The last column shows the eigenvalues for each of the perspectives. See Table 4.

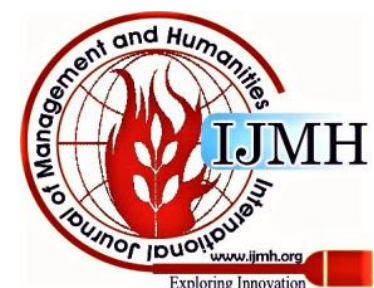


Balanced Scorecard Adaptation using AHP for the Corporate Healthcare Sector in India

Table 4. Eigenvalues for the BSC perspective

\begin{tabular}{|l|c|c|c|c|c|}
\hline \multirow{2}{*}{ Description } & \multicolumn{4}{|c|}{ Weights } & $\begin{array}{c}\text { Eigen } \\
\text { value } \\
\text { (\%) }\end{array}$ \\
\hline $\begin{array}{l}\text { Learning \& } \\
\text { Growth }\end{array}$ & 0.536 & 0.563 & 0.563 & 0.417 & 52 \\
\hline $\begin{array}{l}\text { Internal } \\
\text { Processes }\end{array}$ & 0.178 & 0.188 & 0.188 & 0.250 & 20 \\
\hline Customer & 0.178 & 0.188 & 0.188 & 0.250 & 20 \\
\hline Finance & 0.107 & 0.062 & 0.062 & 0.083 & 8 \\
\hline & & & & Sum & 100 \\
\hline
\end{tabular}

Based on the judgements given by the respondents for the KPIs in all the four perspectives, the weights were calculated by the eigenvector method. The AHP summary sheet is shown in Table 5.

Table 5 AHP summary sheet

\begin{tabular}{|l|r|}
\hline \multicolumn{1}{|c|}{$\begin{array}{c}\text { Balanced Scorecard } \\
\text { Perspectives }\end{array}$} & Weights \\
\hline Learning \& Growth & $33.60 \%$ \\
\hline Empowerment & $31.05 \%$ \\
\hline Employee satisfaction & $21.66 \%$ \\
\hline $\begin{array}{l}\text { Strategic Alliances \& } \\
\text { Partnerships }\end{array}$ & $13.68 \%$ \\
\hline Absenteeism & \\
\hline & \\
\hline Internal Processes & $35.94 \%$ \\
\hline Waiting time & $33.64 \%$ \\
\hline Emergency care & $21.81 \%$ \\
\hline Staff-Patient ratio & $8.61 \%$ \\
\hline Billing time & \\
\hline & $59.83 \%$ \\
\hline Customer & $16.79 \%$ \\
\hline Patient Satisfaction & $14.39 \%$ \\
\hline Skipped appointments & $8.99 \%$ \\
\hline Information access & \\
\hline LAMA \% & $51.67 \%$ \\
\hline & $23.82 \%$ \\
\hline Finance \\
\hline Return on assets & $16.82 \%$ \\
\hline Daily Collections & $7.69 \%$ \\
\hline WC Ratio & \\
\hline Profit & \\
\hline
\end{tabular}

Finally, the BSC was prepared to show the top three KPIs for all the perspectives. These weights are shown against each KPI. See Figure 2

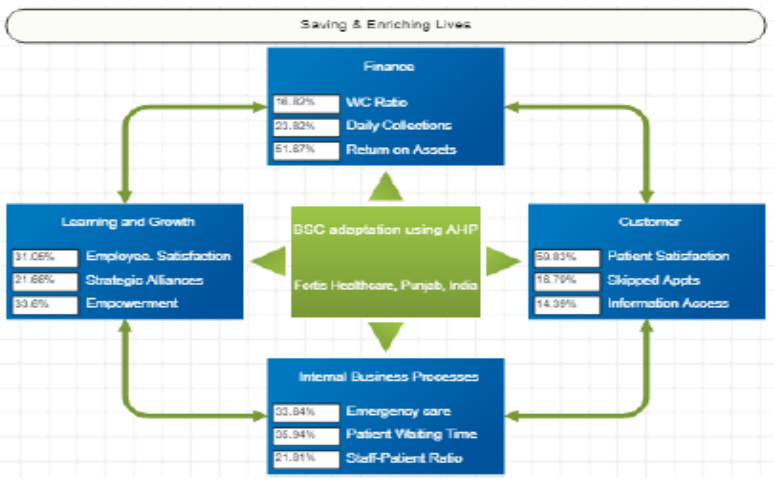

Figure 2: The Balanced Scored with top three KPIs

\section{DISCUSSION}

\section{A. Overall perspectives}

The result of the eigenvector method of calculating the degree of importance of the BSC perspectives indicates that at 52\% Learning \& Growth has the top priority. This confirms the premise that the ability and experience of primarily the doctors and their medical team are crucial to the success of any private healthcare institution. When patients want to be seen and treated by a doctor on whom they have confidence other issues like hospital ambience and waiting times become secondary. The customer(patient) experience becomes pleasant when the treatment by the various staff is professional following established etiquettes. Notably, both Customer and Internal Processes perspectives have equal importance with a score of $20 \%$. When systems and procedures that guide internal processes like billing time and emergency care are efficient, patients are satisfied. A favourable perception of care, by patients is essential to the growth in demand of the healthcare services. The finance perspective is the least important because just focussing on finances without taking care of the employees(learning and growth perspective), patients(customer perspective) and policy implementations(internal processes) will adversely affect income generation.

\section{B. Learning and Growth}

The KPIs 'Employee Empowerment' and 'Employee Satisfaction' have almost equal importance. Both of them are interrelated because with the increase in empowerment satisfaction also increases. The role of human resources in the success of a healthcare venture is emphasised by the importance given to this aspect by the respondents. 'Employee satisfaction' is linked with attrition, performance outcomes, and overall patient experience. It is influenced by interpersonal relationships, working conditions, and compensation. 'Strategic Partnerships' is significant because tie-ups with domain experts can lead to a spurt in the institution's growth. Pioneers need to be identified in applications of medical science and their cutting edge technologies adopted to become market leaders in providing unique services. This can be achieved by entering into a franchise agreement with innovative medical service providers.

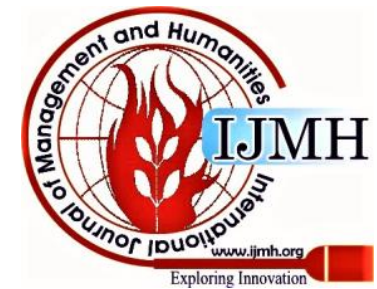




\section{Internal Processes}

Patients who come for treatment expect to be attended to within a reasonable time. This is true particularly when patients require emergency care. Seriously sick patients need to be triaged within 15 minutes of arrival. 'Waiting time' and 'Emergency care' have practically equal importance and should be the primary focus under the Internal Processes perspective. From the expenditure point of view, 'StaffPatient ratio' needs to be kept as low as possible. One of the methods of reducing this ratio is by introducing automation, in areas like transferring samples and diagnostics.

\section{Customer}

At $60 \%$, the percentile for 'Patient Satisfaction' is the highest among all KPIs. Patients are satisfied when the treatment outcomes meet their expectations within the shortest possible time. Favourable outcomes depend upon the accurate diagnosis and appropriate medical interventions. Therefore, it is mandatory to measure and monitor this KPI to see if there is any scope for an increase in patient ratings. Satisfied patients spread positive information about the healthcare institution thereby increasing the flow of new patients requiring medical services. Reduction in patient waiting time requires a coordinated effort between front office staff, nurses, doctors, diagnostics services and billing staff. Long queues in any of these service locations are likely to frustrate patients and adversely affect their perception of the care given. Information access plays a contributory role in patient satisfaction and skipped appointments is an indicator of lower trust in the services provided by the hospital. Hence both these KPIs need attention.

\section{E. Finance}

Among the KPIs in the finance perspective, 'Return on assets(ROA)' has a score of more than $50 \%$. This KPI has become very important due to the changes in the way patients are diagnosed and treatment is given. Medical care has become highly technology-intensive. In both diagnostics(Imaging, Labs etc.) and treatment (Ventilators, Dialysis Machines etc.) huge investments are made. All such assets have a life-time and require close monitoring so that the investments made on them are financially beneficial. Hence the importance of ROA as a KPI. 'Daily Collections' are lead indicators because they are not just past performances but their trends indicate areas where course corrections could be made. Therefore paying attention to them can prevent large fiscal difficulties in the long-term future.

\section{VI.CONCLUSION}

Both literature review and the research work conducted affirm and lead to the conclusion that the adaptation of the BSC incorporating AHP has resulted in a scientifically prepared healthcare performance management tool. With features like flexibility and expandability provided by the BPMSG, healthcare organisations can work on their personalised BSC framework with different KPIs and varied evaluation criteria. Though this study considered only 4 KPIs, a maximum of 10 KPIs for each perspective can be used while using the BPMSG template. This allows expandability of the BSC framework increasing its utility.
For each KPI, the acceptable lower and upper limits can be modified to fit their specific needs. Another significant benefit of this study is the possibility of applying this framework to individual departments of healthcare institutions. Each department of a healthcare organisation can formulate its priority list of KPIs. Further, when within the organisation several departmental priorities need to be compared the Analytic Network Process(ANP) which is a further refinement of the AHP can be used. Thus, by adapting the BSC using AHP and applying them to their strategic initiatives there is scope for several benefits for healthcare institutions.

\section{REFERENCES}

1. J. Steele. Transforming Balanced Scorecard into your Strategy Execution System. Manage. 2001;

2. Niven PR. Balanced scorecard step-by-step for governments and nonprofits. New York: Jon Wiley and Sons; 2003.

3. Samani DZ, Kohan MFZ. Framework for implementing balanced scorecard in hospitals. 2011;5:362-368.

4. Bisbe J, Barrubés J. The Balanced Scorecard as a Management Tool for Assessing and Monitoring Strategy Implementation in Health Care Organizations. Rev Española Cardiol (English Ed. 2012;

5. Kaplan R. Balanced Scorecards Revealed - Becker 's Hospital Review.

6. Ullah HQ, Chow C, Goh M. Towards a dynamic balanced scorecard approach: the case of Changi General Hospital in Singapore. Int J Enterp Netw Manag. 2007;1:230

7. Parmenter D. Key performance indicators developing implementing and using winning KPIs. Wiley; 2001.

8. Saaty TL. Decision making with the analytic hierarchy process. Int Serv Sci. 2008;

9. Jiang Y. Prioritizing and selecting KPIs : translate performance results into managerial actions in strategy making process. 2014;1-25.

10. M. Condorcet. Essay on the Application of Analysis to the Probability of Majority Decisions. , 1785. Impr R - Paris. 1785;

11. Vargas LG. An overview of the analytic hierarchy process and its applications. Eur J Oper Res. 1990

12. Shahin A, Mahbod MA. Prioritization of key performance indicators: An integration of analytical hierarchy process and goal setting. Int $\mathrm{J}$ Product Perform Manag. 2007;56:226-240.

13. Saaty TL. Priority setting in complex problems. IEEE Trans Eng Manag. 2013;

14. Saaty TL. Decision-making with the AHP: Why is the principa eigenvector necessary. Eur J Oper Res. 2003;145:85-91.

15. Chan LY. An Analytic Hierarchy Framework for Evaluating Balanced Scorecards of Healthcare Organizations. Can J Adm Sci. 2006;23:85-104

16. Dey PK, Hariharan S, Despic O. Managing healthcare performance in analytical framework. Benchmarking. 2008;

17. Clinton D, Webber SA, Hassell JM. Implementing the balanced scorecard using the analytic hierarchy process. Manag Account Q. 2002;

18. Goepel KD. Implementing the Analytic Hierarchy Process as Standard Method for Multi-Criteria Decision Making in Corporate Enterprises - a New AHP Excel Template with Multiple Inputs. 2013;1-10.

19. "Duke Space." https://dukespace.lib.duke.edu/dspace/bitstream/ handle/10161/9657/AHP Expert Survey Instructions.docx?sequence=5 (accessed Dec. 09, 2019).

20. Klaus D. Goepel, "Business Performance Management Singapore." https://bpmsg.com/ (accessed Aug. 03, 2020).

21. Saaty TL. The Analytic Hierarchy Process: Planning, priority setting, resource allocation. New York: McGraw-Hill; 1980.

22. Brunelli M. Introduction to the Analytic Hierarchy Process [Internet] Learn. from Fail. 2015. Available from: http://linkinghub.elsevier.com/retrieve/pii/B9780124167278000035.

23. Aguarón J, Moreno-Jiménez JM. The geometric consistency index: Approximated thresholds. Eur J Oper Res. 2003 


\section{Balanced Scorecard Adaptation using AHP for the Corporate Healthcare Sector in India}

\section{AUTHORS PROFILE}

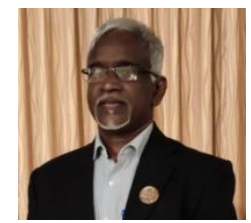

Stephen Victor, B.E.(Mech. Engg.), MBA(HRM) is presently pursuing Ph.D in Aligarh Muslim University (AMU). Associate Professor of Business Management in PCTE, Ludhiana, Punjab. He is experienced in Teaching, Corporate Training, Project Management, and Hospital Administration.

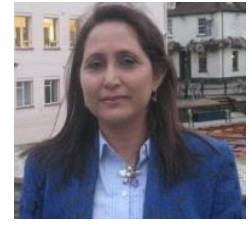

Prof. Ayesha Farooq MBA, $\mathrm{PhD}$ (Management) Professor - Aligarh Muslim University (AMU). Her major themes of research include strategy, balanced scorecard, change management, corporate culture and learning organizations. She has visited the UK (University of Cambridge \& University of Oxford) and may other countries for academic activities.

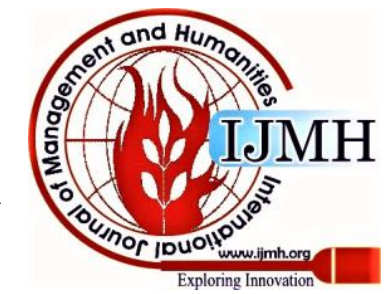

